\title{
Structural Transformations of Low-Temperature Quartz During Mechanoactivation
}

\author{
I. Zhernovsky ${ }^{(\bowtie)}$ and V. Strokova \\ Belgorod State Technological University named after V.G. Shukhov, \\ Belgorod, Russia \\ zhernovsky.igor@mail.ru
}

\begin{abstract}
The paper presents the study of mechanoactivation impact on crystal structure of $\alpha$-quartz. The volume of silicon-oxygen tetrahedron $\mathrm{SiO}_{4}{ }^{4-}$ is accepted as the structural parameter depending on the mechanoactivation degree. The paper compares the dependence of this parameter on temperature, pressure and time of mechanoactivation of $\alpha$-quartz in a planetary mill.
\end{abstract}

Keywords: Quartz $\cdot$ Crystal structure $\cdot$ Silicon-oxygen tetrahedron · Mechanoactivation

\section{Introduction}

The mechanoactivation dispergation of quartz materials is a widespread method of technological processing of this mineral raw material in various fields of technological mineralogy.

In practice of technical petrogenesis of cast stone, forming the basis of synthesis of inorganic silica-containing binding agents (Dmitrieva et al. 2018), the mechanoactivation dispergation of quartz raw material holds a special place.

The result of almost a century-long study of phase and structural transformations of low-temperature quartz during mechanoactivation is the amorphicity of a surface layer of quartz particles and the formation of nanosized $\beta$-quartz crystals in $\alpha$-quartz matrix (Zhernovsky et al. 2018). At the same time there was no study on structural transformations of $\alpha$-quartz within a quartz particle matrix during mechanoactivation. The only exception is the study by Archipenko et al. (1987, 1990) concerning phase transformations in mechanoactivated $\alpha$-quartz. The task of this study is to fill the gap in this matter partially.

\section{Materials and Methods}

The grinding of hydrothermal quartz (Ural) was carried out in the PULVERISETTE 6 classic line planetary mill (Fritsch, Germany) with lining and grinding bodies of tungsten carbide. The milling time made 3, 12, 30, 60, 120, 180, 240, 300 and 360 min. 
The diffraction spectra of samples are obtained using ARL 9900 Workstation $(\lambda \mathrm{Co})$. Shooting interval $-2 \theta^{\circ}: 8-80$, step angle -0.02 . The specification of structural parameters was carried out in DDM v.1.95e software for the difference curve derivative (Solovyov 2004). 174-ICSD data $\left(\mathrm{P}_{2} 21\right)$ were used as a structural model. Profile function - pseudo-Voigt. The specification of the profile parameters was carried out in the anisotropic approximation. Thermal corrections were specified in anisotropic option. Table 1 shows the experimental results.

Table 1. Coordinates of $\alpha$-quartz atoms after mechanoactivation

\begin{tabular}{l|l|l|l|l|l|l|l|l|l}
\hline \multirow{2}{*}{} & \multicolumn{7}{|l|}{ Milling time, min } \\
\cline { 2 - 10 } & 3 & 12 & 30 & 60 & 120 & 180 & 240 & 300 & 360 \\
\hline$S i^{*} x / a$ & 0.4499 & 0.463 & 0.460 & 0.466 & 0.465 & 0.466 & 0.468 & 0.469 & 0.470 \\
\hline$O x / a$ & 0.403 & 0.416 & 0.413 & 0.419 & 0.418 & 0.419 & 0.422 & 0.422 & 0.423 \\
\hline$O \quad y / b$ & 0.2660 & 0.2702 & 0.2697 & 0.2715 & 0.2668 & 0.272 & 0.2697 & 0.2721 & 0.2707 \\
\hline$O z / c$ & 0.7950 & 0.7921 & 0.7919 & 0.7905 & 0.7886 & 0.7868 & 0.7866 & 0.7887 & 0.7876 \\
\hline
\end{tabular}

Note: Si $y / a=0, S i z / c=2 / 3$.

\section{Results and Discussion}

The volume of silicon-oxygen tetrahedrons was chosen as a structural and sensitive quartz parameter on mechanoactivation influence since it depended on several elementary structural parameters: bond length $\mathrm{Si}-\mathrm{O}$, bond angle $\mathrm{O}-\mathrm{Si}-\mathrm{O}$ and twist angle of tetrahedrons (Goryaynov and Ovsyuk 1999).

It is known that mechanoactivation is the result of two processes influencing the material - local thermal influence and impact pressure. Hence, it is advisable to consider structural changes of quartz during mechanoactivation in comparison with changes during thermal and baric impacts. The following were used as references on changes of quartz structural parameters: at a thermal influence - the work of Kihara (1990), at a baric impact - works of Levien et al. (1980), Hazen et al. (1989) and Glinnemann et al. (1992).

The given results show that mechanoactivation alongside with thermal and baric influences transforms the structure of $\alpha$-quartz by reducing the volume of $\mathrm{SiO}_{4}$-tetrahedrons. At the same time the dependences of volumes of $\alpha$-quartz silicon-oxygen tetrahedrons on severity of exposure differ a lot (Figs. 1 and 2).

The energy accumulation by quartz during mechanoactivation, as well as under thermal and baric influence most likely happens due to the reduction of $\mathrm{Si}-\mathrm{O}$ bond length.

The energy accumulated by quartz during mechanoactivation can be estimated by comparing the dependences (Figs. 1a and 2). This comparison confirms that material energy saturation after three-hour mechanoactivation is equivalent to its heating up to $500{ }^{\circ} \mathrm{C}$. 

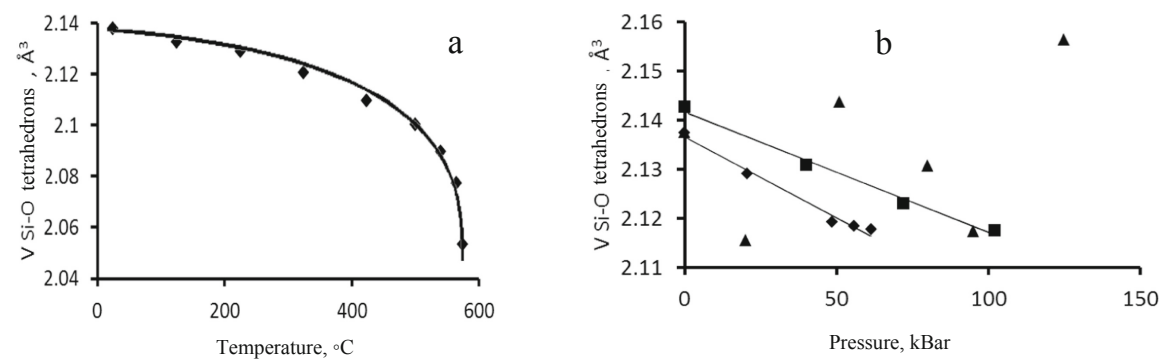

Fig. 1. Calculated dependences of volumes of $\alpha$-quartz silicon-oxygen tetrahedrons on thermal $(a)$ and baric $(b)$ influences. $(b)$ indicates the following data: $\downarrow$-according to Levien et al. (1980), $\boldsymbol{\Delta}$ - according to Hazen et al. (1989), $\mathbf{\square}$ - according to Glinnemann et al. (1992).

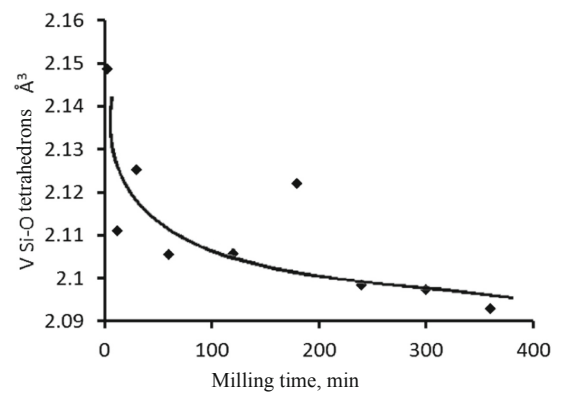

Fig. 2. Dependence of volumes of $\alpha$-quartz silicon-oxygen tetrahedrons on mechanoactivation time

\section{Conclusions}

The change of volume of silicon-oxygen tetrahedrons may be considered as an indicator of the $\alpha$-quartz crystal structure response to the thermal and baric influence, as well as to the mechanoactivation. The difference of these mechanisms of influence is demonstrated by different dependences of this parameter of $\alpha$-quartz crystal structure on the severity of exposure.

Acknowledgements. The work was performed within the Federal Target Program of Research and Development on Priority Development Fields of Science and Technology Sector in Russia for 2014-2020, unique project number: RFMEFI58317X0063. The authors would like to express gratitude to the Doctor of Geology and Mineralogy, Prof. N.V. Zubkova (MSU) for meaningful consultations. 


\section{References}

Archipenko DK, Bokyi GB, Grigorieva TN, Koroleva SM, Yusupov TS (1987) On a new quartz phase stable at room temperature and found during tribo-processing (via $\mathrm{x}$-ray diffraction). Reports of the USSR Academy of Sciences, vol 296, pp 1370-1374

Archipenko DK, Bokyi GB, Grigorieva TN, Koroleva SM, Yusupov TS, Shebanin AP (1990) Deformed quartz structures obtained after mechanoactivation. Reports of the USSR Academy of Sciences, vol 310, pp 874-877

Dmitrieva TV, Strokova VV, Bezrodnykh AA (2018) Influence of the genetic features of soils on the properties of soil-concretes on their basis. Constr Mater Prod 1:69-77

Glinnemann J, King HE, Schulz H, Hahn T, La Placa SJ, Dacol F (1992) Crystal structures of the low-temperature quartz-type phases of $\mathrm{SiO} 2$ and $\mathrm{GeO} 2$ at elevated pressure. Zeitschrift fur Kristallographie 198:177-212

Goryaynov SV, Ovsyuk NN (1999) Twisting of $\alpha$-quartz tetrahedrons at pressure close to transition to an amorphous state. J Exp Theor Phys 69:431-435

Hazen RM, Finger LW, Hemley RJ, Mao HK (1989) High-pressure crystal chemistry and amorphization of alpha-quartz. Solid State Commun 72:507-511

Kihara K (1990) An X-ray study of the temperature dependence of the quartz structure. Eur J Mineral 2:63-77

Levien L, Prewitt CT, Weidner DJ (1980) Structure and elastic properties of quartz at pressure. Am Miner 65:920-930

Solovyov LA (2004) Full-profile refinement by derivative difference minimization. J Appl Crystallogr 37:743-749

Zhernovsky IV, Kozhukhova NI, Lebedev MS (2018) Crystallochemical aspects of technological typomorphism of quartz geomaterials during mechanoactivation. In: The collection of papers: fundamental and applied aspects of technological mineralogy. Under the editorship of Doctor of Geology and Mineralogy V.V. Shchiptsov. Karelian Research Center of the RAS, Petrozavodsk, pp 97-100

Open Access This chapter is licensed under the terms of the Creative Commons Attribution 4.0 International License (http://creativecommons.org/licenses/by/4.0/), which permits use, sharing, adaptation, distribution and reproduction in any medium or format, as long as you give appropriate credit to the original author(s) and the source, provide a link to the Creative Commons license and indicate if changes were made.

The images or other third party material in this chapter are included in the chapter's Creative Commons license, unless indicated otherwise in a credit line to the material. If material is not included in the chapter's Creative Commons license and your intended use is not permitted by statutory regulation or exceeds the permitted use, you will need to obtain permission directly from the copyright holder.

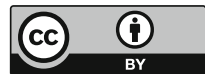

